\title{
Educação em Saúde e Serviço Social: instrumento político estratégico na prática profissional
}

\author{
Marta Alves Santos \\ Centro Universitário da Associação Brasileira de Ensino \\ Universitário (UNIABEU)
}

\author{
Mônica de Castro Maia Senna \\ Universidade Federal Fluminense (UFF)
}

Educação em Saúde e Serviço Social: instrumento político estratégico na prática profissional Resumo: A Educação em Saúde é um dos principais instrumentos do trabalho profissional do assistente social no campo da saúde. Assim sendo, reveste-se das dimensões ético-políticas, teórico-metodológicas e técnico-operativas que norteiam a competência profissional do assistente social que precisam ser mais bem compreendidas para a apreensão crítica da realidade profissional e para subsidiar a intervenção do Serviço Social. Este artigo traz alguns elementos para o debate em torno da Educação em Saúde como um dos instrumentos de trabalho do assistente social na área da saúde. Para tanto, aborda a trajetória histórica da educação em saúde no interior da política de saúde brasileira, destaca os principais paradigmas que têm orientado as ações de Educação em Saúde no país e elenca algumas questões para reflexão sobre a dimensão ético-política da Educação em Saúde como campo de intervenção do assistente social.

Palavras-chave: Educação em Saúde. Serviço Social. Ações socioeducativas.

Education in Health and Social Work: A strategic political instrument in professional practice

Abstract: Education about healthcare is one of the main instruments of the professional work of social assistants in the field of healthcare. It therefore uses ethical-political, theoretical-methodological and technical-operatives, which are dimensions that guide the professional action of social workers and that are essential to a critical understanding of the professional reality and to supporting the intervention of social work. This article raises some elements for the debate about education in health as one of the working instruments of social workers in the field of healthcare. To do so, it addresses the historic trajectory of education in health within Brazilian healthcare policy, highlights the main paradigms that have guided the actions of healthcare in the country and raises some questions for reflection about the ethical-political dimension of education in health as a field of intervention of social workers.

Keywords: Education in health. Social work. Socio-educational actions. 


\section{Introdução}

A área da saúde tem se constituído, ao longo do tempo, em um dos principais campos de atuação profissional do assistente social no Brasil. Dentre as ações desenvolvidas pelo profissional de Serviço Social nessa área, merecem destaque aquelas vinculadas à Educação em Saúde que, embora não exclusivas do assistente social, tem sido uma das mais constantes e frequentemente requisitadas a esse profissional, sobretudo no âmbito da chamada Atenção Primária em Saúde.

Mais do que um procedimento exclusivamente técnico, a Educação em Saúde reveste-se de uma dimensão social e ético-política e, como tal, produz "[...] efeitos reais na vida dos sujeitos" (IAMAMOTO, 1999, p. 67), na medida em que veiculam determinados interesses e compromissos de classe. Isto posto, entende-se que é preciso considerar as concepções, finalidades e objetivos que orientam tais ações.

É possível identificar diferentes concepções de Educação em Saúde que se colocam em disputa ao longo da trajetória da política de saúde no país. Em linhas gerais, pode-se afirmar que a concepção hegemônica baseia-se em uma noção restrita do processo saúde-doença a seus aspectos biológicos, reforçando a responsabilidade individual na promoção e garantia da saúde. Desse modo, a Educação em Saúde tende a se constituir em um instrumento de dominação e de afirmação do saber dominante, visando apenas à integração do usuário às condições sociais, políticas e econômicas em que vive. Ao mesmo tempo, desconsidera a perspectiva ampliada de saúde como produto das relações sociais vigentes, tal como defendida pelo movimento da Reforma Sanitária brasileira a partir dos anos 1970.

Outras formas de conceber e de trabalhar a Educação em Saúde têm desafiado a concepção hegemônica, contribuindo para o reconhecimento da saúde como um processo de construção coletiva e dos sujeitos envolvidos como autores de sua própria história. Tais concepções advogam que a Educação em Saúde não se operacionaliza pela mera transferência de informação, o que reforça a subalternização dos usuários, mas, ao contrário, pode contribuir para enfatizar a participação social dos usuários e produzir conhecimento crítico da realidade. Segundo Nogueira e Mioto (2006), a Educação em Saúde e sua promoção estão vinculadas à eficácia da sociedade em efetivar, de fato, a implantação de políticas públicas voltadas para a qualidade de vida e ao desenvolvimento da capacidade de contextualizar criticamente a conjuntura em que está inserida, a fim de contribuir para a transformação real dos fatores determinantes da condição de saúde. Uma proposta de Educação em Saúde objetiva socializar o conceito de consciência sanitária.

Torna-se fundamental, desse modo, que o profissional de Serviço Social priorize ações coletivas que democratizem informações e conhecimentos necessários para a promoção, prevenção e recuperação da saúde, a partir de uma prática educativa crítica, que fortaleça a autonomia dos sujeitos e que seja construída por dois sujeitos sociais: profissionais e usuários.

Esse artigo busca contribuir nessa direção, trazendo elementos para o debate em torno da Educação em Saúde como um dos instrumentos de trabalho do assistente social na área da saúde. Inicialmente, aborda a trajetória histórica da educação em saúde no interior da política de saúde brasileira. Em seguida, destaca os principais paradigmas que têm orientado as ações de Educação em Saúde no país. Por fim, elenca algumas questões para reflexão sobre a dimensão ético-política da Educação em Saúde como campo de intervenção do assistente social.

\section{Educação em Saúde na trajetória histórica da política de saúde brasileira}

Entende-se que as concepções de Educação em Saúde estão profundamente imbricadas com os modelos de atenção à saúde constituídos no Brasil, os quais, por sua vez, são parte integrante dos processos sociais, políticos e econômicos mais amplos em diferentes contextos históricos. Nesse sentido, cabe reconhecer que a emergência da Educação em Saúde como campo de prática se dá de forma articulada ao que vem a se constituir a Saúde Pública no Brasil (MARQUES, 2006).

No início do século XX, o Estado brasileiro amplia suas ações dirigidas à coletividade, visando a combater as epidemias que atingiam os interesses econômicos das elites dominantes, em especial os setores da produção e exportação de café e da incipiente indústria nacional. Institucionalizava-se a Saúde Pública como área de intervenção estatal, dando ênfase a medidas higienistas de saneamento e controle de doenças, elegendo os cortiços - local de moradia da classe trabalhadora de mais baixa renda - como foco central das intervenções sanitárias. Predominavam percepções que imputavam à classe trabalhadora a responsabilidade pela falta de higiene, pela ausência de saneamento e pela precariedade das condições de vida.

Dentro desse contexto, a Educação em Saúde ganha força como importante mecanismo de normalização de comportamentos das classes populares, assumindo um caráter disciplinador e repressivo. Como salientam Smeke e Oliveira (2001, p. 118), no Brasil, a Educação em Saúde "tem origem marcada por um discurso 
e prática normatizadores. Esses discursos operavam no sentido de uma conduta racional e laica perante a doença, contrapondo-se à ideologia místico-religiosa, então predominante".

Essa tendência é realçada nas análises de Costa (1984, p. 7), ao afirmar que

A estratégia de educação em saúde foi regulamentar, enquadrar, controlar todos os gestos, atitudes, comportamentos, hábitos e discursos das classes subalternas e destruir ou apropriar-se dos modos e usos do saber estranhos a sua visão do corpo, da saúde, da doença, enfim, do 'bom' modo de andar a vida.

O caráter extremamente autoritário das práticas educativas no período foi destacado por Silva et al. (2010), que identificam a influência do modelo alemão da Polícia Médica. De acordo com os autores, nesse contexto foi criada a política sanitária no Brasil com atuação assentada no discurso da higiene com imposição de normas e regras.

Inflexões ganham vulto a partir dos anos 1930, quando o Brasil dá impulso ao processo de industrialização e o Estado passa a intervir na questão social. Com a criação dos Institutos de Aposentadoria e Pensão (IAP), tem início a atenção sanitária voltada aos trabalhadores, demarcando o padrão dual de organização da política de saúde que vigoraria até a Constituição Federal de 1988, caracterizado, em linhas gerais, pela conjugação de ações de saúde pública, de caráter preventivo e voltado às coletividades a ações de assistência médica com enfoque individual e predominantemente curativa (BRAVO, 2004).

No campo específico da Educação em Saúde, assiste-se, no período, ao avanço da influência norteamericana, por meio do desenvolvimento da educação sanitária. Essa perspectiva criticava o modelo autoritário anterior, apontando sua baixa eficácia diante de demandas relacionadas à saúde da criança e do trabalhador que se apresentavam naquele momento. Assim, propunha ações persuasivas e de conscientização em que os métodos educativos eram propostos com base na crença de que boas condições de saúde passavam pela consciência sanitária dos indivíduos (SILVA et al., 2010).

Com forte influência eugenista, a educação sanitária foi introduzida nas escolas públicas brasileiras, tendo por base a concepção de que aspectos de moral e bom comportamento possibilitariam o ajuste dos indivíduos a uma vida considerada normal perante a sociedade. De acordo com Silva et al. (2010), entendia-se que o acesso a informações sobre hábitos saudáveis levaria aos setores populares a consciência sobre comportamentos insalubres e isso seria suficiente para mudanças nesses comportamentos.

Essa tendência é reforçada nos anos seguintes, no bojo do fortalecimento do denominado sanitarismodesenvolvimentista. Trata-se, em linhas gerais, de uma ideologia baseada na crença de que o nível de saúde de uma dada sociedade está atrelado ao grau de desenvolvimento do país. Nesse sentido, as ações de educação em saúde são enfatizadas como estratégicas para melhorar as condições socioeconômicas da população, ancoradas no plano disciplinador, individual e cultural.

A ditatura militar interrompeu os intentos participacionistas que caracterizaram a ação estatal do período populista. Há reformulações importantes no sistema de saúde brasileiro, com unificação dos IAP no Instituto Nacional da Previdência Social (INPS) e posterior incorporação ao Sistema Nacional da Previdência Social (SINPAS). Como sinaliza Bravo (2007), tratava-se de um processo de modernização estatal, em que o Estado aumentava seu poder regulatório sobre a sociedade e, ao mesmo tempo, desmobilizava as forças políticas que estavam em cena no período anterior.

Durante o período ditatorial, a política de saúde privilegiou o setor privado, por meio de um dado padrão de intervenção estatal que incentivava a extensão da cobertura previdenciária via oferta privada e financiamento público. Consolidava-se a hegemonia do modelo médico curativo, hospitalocêntrico, individual e especializado, por meio da articulação do Estado aos interesses das indústrias farmacêuticas, de equipamentos médicos e seguros saúde.

Em contraposição ao regime autoritário, ganhava terreno uma abordagem histórico-estrutural dos problemas de saúde, impulsionada pelos Departamentos de Medicina Preventiva das Faculdades de Medicina e pela crescente efervescência dos chamados novos movimentos sociais. Afirmava-se a noção de saúde-doença como um processo socialmente determinado, chamando atenção para aspectos-chave como sua articulação com o mundo do trabalho, a prática social da medicina e a tendência de medicalização da sociedade. Ao mesmo tempo, cresciam as críticas ao Estado autoritário e ao modelo médico hegemônico, com defesa da mobilização e participação da sociedade civil.

Nesse contexto, há uma reformulação no campo da Educação em Saúde. De acordo com Marques (2006), mudanças na nomenclatura do campo indicavam diferentes concepções e orientações para o desenvolvimento das ações educativas na área da saúde. Há uma tendência à adoção de uma perspectiva mais democrática, em grande parte impulsionada pelo emergente movimento sanitário. Todavia, foram grandes as resistências por parte dos segmentos hegemônicos, principalmente das indústrias farmacêuticas e da Federação 
Brasileira de Hospitais, que se articulavam aos governos militares e assumiam a hegemonia no processo decisório em torno da política de saúde.

Nesse contexto, cabe destacar a influência recebida do método de Educação Popular, elaborado por Paulo Freire (1987, 2014), para o desenvolvimento da Educação em Saúde. Este método se ancora na aliança entre técnicos e classes populares, valorizando o saber popular e considerando essa aliança uma troca de experiências de saberes diferenciados. Mais ainda, a Educação em Saúde passou a ser vista como um processo capaz de possibilitar a conscientização dos grupos sociais desfavorecidos sobre suas condições de vida e saúde e, desse modo, uma estratégia fundamental para a superação de tais condições (MARQUES, 2006).

Sob essa ótica, e referenciadas pela Conferência Internacional sobre Cuidados Primários em Saúde ocorrida em Alma Ata no ano de 1979, várias experiências locais em torno da saúde foram desenvolvidas pelo país, sendo a Educação em Saúde importante eixo aglutinador para onde convergiam iniciativas de resistência e oposição ao regime militar.

No contexto de transição democrática da década de 1980, a luta pela saúde pública se ampliou no Brasil, e as propostas advindas de várias manifestações sociais ganharam visibilidade. Nesse período, eventos importantes na área da saúde revelaram um campo de tensão constante entre os interesses de cunho capitalista e aqueles postos pelas mobilizações que buscavam implementar uma política sanitária mais igualitária.

Um marco nesse processo foi a $8^{\mathrm{a}}$ Conferência Nacional de Saúde (CNS), ocorrida em 1986 e que contou com a participação não apenas de setores do governo - como era até então - mas, de forma então inédita, com profissionais de saúde e representantes dos movimentos sociais. Denunciando as precárias condições de organização da atenção à saúde e reivindicando maior responsabilização pública e níveis de equidade e justiça social, o relatório final da $8^{\mathrm{a}} \mathrm{CNS}$ encampou os princípios da participação, da equidade, da integralidade e da universalização, que serviram de base para a elaboração do capítulo da saúde na Constituição de 1988.

O campo da Educação em Saúde também sofreu influências do clima democrático que se destacava no país. Propostas com ideais inovadores se confrontavam com o modelo tradicional de educar no âmbito da saúde. Segundo Silva et al. (2010), novas abordagens em educação em saúde buscavam promover o crescimento da capacidade crítica da realidade, como também, aperfeiçoar formas de lutas, resistência e enfrentamento. A partir de um olhar crítico e pedagógico, a educação em saúde adquiriu um perfil democrático que possibilitou fomentar a participação e as ações coletivas em direção à perspectiva de transformação social.

Mas a tensão entre concepções distintas sobre Educação em Saúde se faz presente no processo de construção e consolidação do Sistema Único de Saúde (SUS), esse também atravessado por disputas entre projetos distintos. Verificam-se continuidades e também mudanças em relação aos princípios defendidos pela Reforma Sanitária brasileira, com avanços importantes em termos de cobertura das ações sanitárias, do processo de descentralização e pactuação entre os três níveis de governo e da ampliação da arena decisória, dentre outros. No entanto, o subfinanciamento setorial, o potente viés mercadológico da saúde e a expansão do subsistema privado, em grande parte subvencionada por recursos públicos, configuram limites estruturais às mudanças no modelo de atenção e de gestão pública.

A implantação da Estratégia Saúde da Família e a institucionalização das Políticas Nacionais de Atenção Básica - PNAB (BRASIL, 2006a), de Promoção da Saúde (BRASIL, 2006b) e de Educação Popular em Saúde - PNEPS (BRASIL, 2012) - iniciativas que ganham potência na segunda metade dos anos 2000 abrem espaço para o fortalecimento da Educação em Saúde, sendo marcadas pela tensão entre concepções mais restritas que associam as práticas educativas à mera transmissão de conhecimento ou mudança de comportamentos e abordagens que enfocam a participação, o diálogo, a troca de saberes e a busca da emancipação e da autonomia dos sujeitos. Esse rumo significa enfocar a participação na saúde como ferramenta para efetivar uma política de saúde mais democrática e equitativa.

\section{Educação em Saúde no Brasil: principais paradigmas}

Como demonstra sua trajetória histórica, a Educação em Saúde assume concepções diversas em diferentes contextos sociais. Concepções essas que incidem na forma de agir e implementar ações socioeducativas, na medida em que expressam modelos distintos e mesmo divergentes. A literatura que trata da Educação em Saúde tem sido unânime em identificar a existência de duas grandes matrizes de abordagem ou modelos de Educação em Saúde que têm influenciado as práticas sanitárias no Brasil: o chamado modelo tradicional e o modelo dialógico. Essas matrizes tendem a assumir posições polares no debate em torno da temática da Educação em Saúde.

Nesses termos, caracteriza-se o modelo tradicional de educar em saúde como um modelo de educação bancária, em que a função do educador é depositar conteúdos aos educandos. A educação torna-se verticalizada 
e o educador disciplina, prescreve sua opção, dita e escolhe o conteúdo programático. Enfim, o educador é sujeito do processo e os educandos, meros objetos que se submetem a ele.

A educação, no âmbito da saúde, construiu sua história sob esse molde tradicional. Os educandos são considerados carentes de informação em saúde e a eles são prescritos hábitos e comportamentos ditos como saudáveis. São ditadas normas e regras de como agir para manter a saúde. Tal fato procede com a memorização do conteúdo narrado pelo educador.

Normas e regras ditadas perpassam pela relação de poder. Tomando por referência o trabalho de Foucault (1979), entende-se que o poder está em toda parte, pois ele não existe sozinho em si. O poder funciona e materializa-se através das práticas e relações sociais. Há certa funcionalidade do poder que não está alocado em determinado lugar, mas perpassa por todos os lugares, pelas relações que se estabelecem na sociedade.

O modelo tradicional de educar em saúde não apresenta o poder como repressor, pois Foucault (1979) afirma que existe outro lado do poder. A concepção de que o poder produz saber, pois nesse processo poder/ saber há o sujeito que conhece e outro que recebe as informações e necessita adquirir conhecimento. Há, portanto, um processo de disciplinamento.

O modelo tradicional que dita normas aos usuários da saúde segue essa linha de pensamento alicerçado na disciplina. Torna-se visível o controle do corpo, dos seus gestos e comportamentos, pelas técnicas de poder que são concebidas como disciplina, configurando-se uma relação de adestramento. Essa forma de educar cria usuários submissos e dóceis em termos de aceitação do que é dito e de obediência. O indivíduo não é sujeito de ação, é um depósito bancário de informações, nos termos de Freire (1987) ou um produto de disciplina, conforme Foucault (1979). Além disso, desconsidera a realidade dos usuários, tornando a prática educativa lassa e acrítica.

No entanto, há outros modelos de Educação em Saúde que surgem no Brasil como forma de resistência ao modelo tradicional. Trata-se do modelo dialógico, que apresenta o diálogo como fundamento teórico e metodológico e torna o usuário protagonista da prática educativa. Em outros termos, o educando torna-se sujeito de sua própria história, responsável também pela construção de novos posicionamentos no processo saúde-doença-cuidado. Portanto, tende a estabelecer interlocução e uma visão crítica da realidade, das demandas e serviços de saúde, fortalecendo as condições de possíveis estratégias de transformação.

Segundo Vasconcelos, E. M. (2011), o diálogo delineia soluções e orienta as práticas educativas, contribuindo para a superação do biologicismo, da autoridade do profissional de saúde e do enfoque restrito na doença. O modelo dialógico busca a construção ampliada de saúde no campo sanitário. $\mathrm{O}$ autor afirma que a educação popular em saúde é percebida como estratégia de construção de uma saúde mais adequada à vida da população e utiliza o diálogo como um dos seus atributos. Tendo como base esse paradigma, o processo educativo na saúde não viabiliza apenas a produção de uma nova consciência sanitária, mas também for-

A Educação em Saúde que aponta o diálogo como eixo central do processo educativo inscreve a educação popular em saúde como instrumento de gestão participativa da ação social. Surge como processo inovador de práticas educativas que tende a romper com o modelo tradicional. talece e favorece a democratização das políticas públicas. Autores como Figueiredo, Rodrigues Neto e Leite (2010) e Alves (2005) descrevem o profissional de saúde como um educador que estimula a autonomia dos usuários, reconhecendo-o como sujeito de sua história e do processo educativo em saúde.

A Educação em Saúde que aponta o diálogo como eixo central do processo educativo inscreve a educação popular em saúde como instrumento de gestão participativa da ação social. Surge como processo inovador de práticas educativas que tende a romper com o modelo tradicional.

Tais experiências inovadoras nas práticas educativas eram construídas a partir do diálogo entre o saber popular e o acadêmico, e já nos anos 1970 muitos profissionais da saúde faziam interlocução com os movimentos sociais das periferias urbanas e territórios rurais. Vasconcelos, A. C. C. P. (2013) relata que nesse período iniciavam-se experiências inovadoras de serviços comunitários que, desassociados do Estado, ampliavam relações com grupos populares, considerando a dinâmica local da região.

Nesse prisma, vários segmentos de profissionais de saúde buscam, a partir dos anos 1970, uma ruptura com o modelo tradicional e autoritário de Educação em Saúde que dita normas e disciplinas aos usuários. Surge no âmbito sanitário uma nova cultura de relação com as classes populares, que insere um ambiente de troca de saberes e diálogo entre os sujeitos do processo educativo. Muitas dessas experiências educativas 
contribuíram para fortalecer e disseminar as proposições em torno da Reforma Sanitária brasileira. Não é exagerado afirmar que muitos dos profissionais que atuavam no campo da Educação Popular em Saúde integravam o chamado movimento sanitário.

Com a implantação do SUS ao final da década de 1980 - e seus princípios da universalidade, equidade e integralidade -, as experiências de educação popular em saúde continuaram a persistir em favor de política de saúde mais igualitária e participativa. Muitos profissionais engajados com a luta pela efetivação do SUS adotaram a metodologia de educação popular em saúde como estratégia para o fortalecimento da participação popular na gestão e na orientação de novas formas de conduzir a política pública de saúde.

Segundo Vasconcelos, E. M. (2013), a educação popular não busca criar sujeitos subalternos polidos, limpos e bebendo água fervida. Seu propósito é estimular a participação para a organização do trabalho político que abre os caminhos para as conquistas dos direitos. O objetivo desse processo educativo consiste em apurar, organizar, aprofundar o pensar e o agir dos diversos sujeitos subalternos à lógica da sociedade. O pensar e o agir a partir de uma visão crítica tornam-se eixos fundantes na construção de uma sociedade solidária e justa. Segundo Vasconcelos, E. M. (2013), a educação popular pode ser sintetizada como a formação de pessoas mais críticas e dispostas a almejar uma melhor contribuição a sua condição econômica, cultural, política e sanitária.

No entanto, para formar pessoas críticas que redesenham as relações sociais existentes, a educação popular inscreve um novo modelo de operacionalizar ações educativas. Não é coerente impor conteúdo, objetivos, regras de comportamentos e atitudes vistas como as corretas, mas também não é a veneração da cultura popular. Há, portanto, a troca, o intercâmbio das experiências e da participação, e nessa dinâmica o diálogo torna-se peça fundamental.

Sob essa luz, a educação popular em saúde abrange a integralidade de forma mais precisa e ampliada, pois as abordagens em diversas dimensões recaem além dos problemas pessoais. Abarcam dimensões políticas, culturais, econômicas, locais e societárias. Vasconcelos, E. M. (2013) afirma que a educação popular em saúde é instrumento de promoção voltado para a formação da cidadania ativa.

Para tanto, o cotidiano em saúde necessita ser trabalhado e desvelado em suas variadas dimensões no caminho da construção da democracia, da justiça, da solidariedade e da superação das múltiplas expressões da desigualdade social. No entanto, seguir nesses rumos significa encarar desafios constantes do dia a dia profissional, principalmente no âmbito do SUS.

\section{Educação em Saúde como potencializador político no Serviço Social}

Ao se considerar a Educação em Saúde como um dos instrumentos centrais do trabalho profissional do assistente social no âmbito da saúde, torna-se necessário reconhecer que a mesma é constituída pelas dimensões ético-políticas, teórico-metodológicas e técnico-operativas que modelam o trabalho profissional. Nessa direção, mais do que uma questão de ordem exclusivamente técnica, a Educação em Saúde está diretamente relacionada aos projetos societários presentes e em disputa em determinado momento histórico.

Ao realizar um estudo sobre a produção bibliográfica do Serviço Social referente às ações socioeducativas, Lima e Mioto (2011) assinalam que a partir do Movimento de Reconceituação do Serviço Social no Brasil, tais ações são enfatizadas com base no reconhecimento de seu potencial para o fortalecimento de processos emancipatórios.

Com ela [a ênfase nas ações socioeducativas] espera-se contribuir para a formação de uma consciência crítica entre sujeitos, através da apreensão e vivência da realidade, para a construção de processos democráticos, enquanto espaços de garantia de Direitos, mediante a experiência de relações horizontais entre profissionais e usuários. Nesse processo educativo, projeta-se a emancipação e a transformação social. (LIMA; MIOTO, 2011, p. 217-218).

No entanto, como chamam atenção as autoras, é preciso atentar para a armadilha, bastante comum na profissão, de considerar que a simples invocação dos princípios de autonomia, emancipação e participação é condição suficiente para que projeto ético-político da profissão se materialize nas ações socioeducativas.

Como mencionado, a educação popular em saúde no SUS busca não apenas reverter o quadro de saúde da população envolvida, como também fortalecer e intensificar a participação, o que viabiliza a democratização das políticas públicas e da promoção da saúde. Nesse sentido, essa perspectiva se articula aos princípios que orientaram a criação do SUS, quando se tem como referência a participação, a promoção e as ações integradas como componentes fundantes do sistema público de saúde. 
Nesse contexto é importante o trabalho profissional do assistente social no que tange à Educação em Saúde, entendendo-o enquanto um profissional da saúde que atua nas relações sociais entre os sujeitos e no seu cotidiano, através de uma ação socioeducativa que objetiva desenvolver educação permanente em saúde, a fim de socializar e democratizar informações. Vasconcelos, A. M. (2006) registra que uma proposta socioeducativa do profissional de Serviço Social na saúde politiza as demandas, enfatiza a participação social dos usuários, produz o conhecimento crítico da realidade e aposta na constante busca da autonomia dos sujeitos sociais. Por isso, reforça-se a ideia que a Educação em Saúde deve ser pensada como instrumento teórico-metodológico e ético-político do exercício profissional, que pode fomentar sua transformação qualitativa em direção aos interesses dos usuários e à satisfação das necessidades dos segmentos menos favorecidos.

$\mathrm{O}$ ato da Educação em Saúde pode contribuir para o profissional de Serviço Social articular as diversas mediações e contradições que surgem no cotidiano dos espaços sócio-ocupacionais, potencializando outras formas de condução das dimensões metodológicas e políticas que transforme a realidade. Nesse sentido, o assistente social deve conhecer a realidade do usuário e priorizar ações educativas coletivas que apostem na emancipação humana. Evidencia-se, portanto, o caráter essencialmente político do exercício profissional do Serviço Social. Assinala-se a relevância do desenvolvimento de ações mediadoras pedagógicas, ético-políticas que contribuam para formação da sensibilidade crítica dos usuários.

A prática profissional do assistente social possui dimensão socioeducativa e fomenta a operacionalização do projeto ético-político da profissão, o que pode viabilizar meios de construir a transformação social no cotidiano dos usuários.

\section{Considerações Finais}

A partir do exposto, observa-se que a Educação em Saúde é atravessada por concepções e propostas distintas e mesmo antagônicas, que se colocam em disputa ao longo de sua trajetória histórica. Longe de se constituir em uma perspectiva ultrapassada, abordagens disciplinadoras, normalizadoras e estigmatizantes de educação em saúde se fazem presentes na atuação profissional na cena contemporânea, sendo desafiadas por outros enfoques, em que as ações de educação em saúde configuram-se em eixo articulador entre a análise crítica da realidade social e a busca de possibilidades de transformá-la.

À dimensão técnico-operativa e teórico-metodológica que reveste esse campo de atuação profissional, associa-se a dimensão ético-política, as quais estão profundamente imbricadas entre si. Tal imbricação permite romper com noções que restringem a educação em saúde a um ato voluntarista por parte de seus agentes, recuperando interseções entre as condições objetivas do fazer profissional ao compromisso ético-político profissional.

Enfatiza-se, nesse sentido, que a educação em saúde apresenta potencial para o fortalecimento de processos emancipatórios dos sujeitos envolvidos, em direção à formação de uma consciência crítica da realidade, à garantia de direitos e à transformação social. De fato, o assistente social pode operacionalizar uma prática educativa e interventiva a partir da leitura crítica da realidade em que atua, reconfigurando, portanto, ideias e ações que perpassam a dinâmica social marcada por contradições e correlações de forças. Igualmente, pode integrar e fomentar formas de participação da população no contexto de sua vida cotidiana, mediante a construção de processos democráticos baseados no estabelecimento de relações horizontais entre profissionais e usuários.

Encaminhar uma sistematização da prática profissional no âmbito da saúde que reforce o projeto éticopolítico da profissão pode contribuir para a viabilização de práticas educativas potencializadoras nos rumos da participação, autonomia e visão crítica da realidade e na construção de novas relações sociais no âmbito sanitário.

No entanto, trilhar esses rumos significa superar desafios postos pelo atual contexto de acumulação capitalista e sua expressão na sociedade brasileira, que atingem as políticas públicas como um todo, não deixando a saúde isenta desse processo. Diante de tempos sombrios, cada vez mais se faz necessário apostar no coletivo nas formas de intervenção, nas estratégias de fortalecimento da mobilização e na participação dos usuários onde os grupos educativos podem ser estratégicos desse processo. Em suma, há de se apostar no acompanhamento das dinâmicas societárias, como também na capacitação permanente dos profissionais de Serviço Social.

\section{Referências}

ALVES, V. S. Um modelo de atenção em saúde para a Saúde da Família: pela integralidade da atenção e reorientação do modelo assistencial. Interface, Botucatu, v. 9, n. 16, p. 39-52, set. 2004/fev. 2005. Disponível em: <http://www.scielo.br/pdf/icse/v9n16/ v9n16a04.pdf >. Acesso em: 7 ago. 2016.

BRASIL. Ministério da Saúde. Secretaria de Gestão Estratégica e Participativa. Política Nacional de Educação Popular em Saúde. 
Brasília, DF: Ministério da Saúde, 2012. Disponível em: <http://www.crpsp.org.br/diverpsi/arquivos/PNEPS-2012.PDF>. Acesso em: 9 mar. 2014.

Secretaria de Atenção Básica. Departamento de Atenção Básica. Política Nacional de Atenção Básica. Brasília, DF: Ministério da Saúde, 2006a. Disponível em: $<$ http://bvsms.saude.gov.br/bvs/publicacoes/politica_nacional_atencao_basica_2006.pdf > Acesso em: 7 ago. 2016.

Secretaria de Vigilância em Saúde. Departamento de Análise de Situação e Saúde. Política Nacional de Promoção da Saúde. Brasília, DF: Ministério da Saúde, 2006b. Disponível em: <http://www.pmf.sc.gov.br/arquivos/arquivos/pdf/ $28 \quad 11 \quad 2013 \quad$ 14.57.23.7ae506d47d4d289f777e2511c83e7d63.pdf>. Acesso em: 9 mar. 2014.

BRAVO, M. I. Saúde e Serviço Social. São Paulo: Cortez; UERJ, 2004.

. Serviço Social e reforma sanitária: lutas sociais e práticas profissionais. 2. ed. São Paulo: Cortez, 2007.

COSTA, N. do R. Lutas urbanas e controle sanitário. Petrópolis: Vozes, 1984.

FIGUEIREDO, M. F. S.; RODRIGUES NETO, J. F.; LEITE, M. T. S. Modelos aplicados às atividades de Educação em Saúde. Revista Brasileira de Enfermagem, Brasília, v. 63, n. 1, p. 117-121, jan./fev. 2010. Disponível em: <http://www.scielo.br/pdf/reben/v63n1/ v63n1a19.pdf>. Acesso em: 7 ago. 2016.

FOUCAULT, M. O nascimento da Medicina Social. In: ____. Microfisica do poder. Rio de Janeiro: Graal, 1979. p. 79-98.

FREIRE, P. Pedagogia e autonomia: saberes necessários à prática educativa. Rio de Janeiro: Paz e Terra, 1987. Pedagogia do Oprimido. 56. ed. Rio de Janeiro: Paz e Terra, 2014.

IAMAMOTO, M. V. O Serviço Social na contemporaneidade: trabalho e formação profissional. 2. ed. São Paulo: Cortez, 1999.

LIMA, T. C. S. de; MIOTO, R. C. T. Ações socioeducativas e Serviço Social: características e tendências na produção bibliográfica. Temporalis, Brasília (DF), v. 11, n. 21, p. 211-237, jan./jun. 2011. Disponível em: <http://periodicos.ufes.br/temporalis/article/view/ 1378/1634>. Acesso em: 7 ago. 2016.

MARQUES, D. L. Educação em Saúde na Atenção Básica: concepções dos profissionais médicos do Programa Médico de Família de Niterói - RJ. 2006. Dissertação (Mestrado em Política Social) - Escola de Serviço Social, Universidade Federal Fluminense, Niterói, 2006. NOGUEIRA, V. M. R.; MIOTO, R. C. Desafios atuais do Sistema Único de Saúde - SUS e as exigências para os Assistentes Sociais. In: MOTA, A. E. et al. (Org.). Serviço Social e saúde: formação e trabalho profissional. São Paulo: Cortez, 2006. p. $218-241$.

SILVA, C. M. da C. et al. Educação em saúde: uma reflexão histórica de suas práticas. Ciência \& Saúde Coletiva, Rio de Janeiro, v. 15, n. 5, p.2539-2550, 2010. Disponível em: <http://www.scielo.br/pdf/csc/v15n5/v15n5a28.pdf>. Acesso em: 7 ago. 2016.

SMEKE, E. de L. M.; OLIVEIRA, N. L. S. Avaliação participante de práticas educativas em serviços de saúde. Cadernos CEDES, Campinas, v. 29, n. 79, p. 347-360, set. 2001. Disponível em: <http://www.cedes.unicamp.br>. Acesso em: 7 ago. 2016.

VASCONCELOS, A. C. C. P. Práticas Educativas em Segurança Alimentar e Nutricional: a experiência da Estratégia Saúde da Família em João Pessoa - PB. 2013. 281 f. Tese (Doutorado em Ciências na área de Saúde Pública) - Escola Nacional de Saúde Pública Sérgio Arouca, Fundação Oswaldo Cruz, Rio de Janeiro, 2013.

VASCONCELOS, A. M. Serviço Social e práticas democráticas na saúde. In: MOTA, A. E. et al. (Org.). Serviço Social e saúde: formação e trabalho profissional. São Paulo: Cortez, 2006. p. 242-272.

VASCONCELOS, E. M. Espiritualidade na Educação Popular em Saúde. Cadernos CEDES, Campinas, v. 29, n. 79, p. 323-334, set./ dez., 2011. Disponível em: <http://www.scielo.br/pdf/ccedes/v29n79/03.pdf >. Acesso em: 7 ago. 2016.

. Educação Popular em Saúde: de uma prática subversiva uma estratégia de gestão participativas das políticas de saúde. In: STRECK, D. R.; ESTEBAN, M. T. (Org.). Educação Popular: lugar de construção social coletiva. Petrópolis, RJ: Vozes, 2013. p. 110-127.

\section{Marta Alves Santos}

santosmarta960@gmail.com

Doutorado em Política Social pela Universidade Federal Fluminense (UFF)

Assistente Social da Prefeitura Municipal de Niterói

Professora do Centro Universitário da Associação Brasileira de Ensino Universitário (UNIABEU)

\section{UNIA BEU}

Rua Desembargador Athayde Parreiras, 266 - Bairro de Fátima

Niterói - Rio de Janeiro - Brasil

CEP: 24.070-090

\section{Mônica de Castro Maia Senna}

monica.senna20@gmail.com

Doutorado em Ciências - Saúde Pública pela Escola Nacional de Saúde Pública Sergio Arouca, da Fundação Oswaldo Cruz (ENSP/ FIOCRUZ) 
Professora Associada da Escola de Serviço Social e do Programa de Estudos Pós-graduados em Política Social da Universidade Federal Fluminense (UFF)

\section{UFF}

Rua Professor Marcos Waldemar de Freitas Reis, s/n. - Bloco E $-3^{\circ}$ andar Campus Universitário do Gragoatá - Bairro São Domingos

Niterói - Rio de Janeiro - Brasil

CEP: 24.210-201 